\title{
Team Teaching of Creative Advertising and Public Relations Courses
}

Pamela K. Morris

Loyola University Chicago, pmorris1@luc.edu

Follow this and additional works at: https://ecommons.luc.edu/communication_facpubs

Part of the Communication Commons

\section{Recommended Citation}

Morris, Pamela K.. Team Teaching of Creative Advertising and Public Relations Courses. Journal of Advertising Education, 20, 1-2: 44-53, 2016. Retrieved from Loyola eCommons, School of Communication: Faculty Publications and Other Works,

This Article is brought to you for free and open access by the Faculty Publications and Other Works by Department at Loyola eCommons. It has been accepted for inclusion in School of Communication: Faculty Publications and Other Works by an authorized administrator of Loyola eCommons. For more information, please contact ecommons@luc.edu.

\section{cc) (i) $\ominus$}

This work is licensed under a Creative Commons Attribution-Noncommercial-No Derivative Works 3.0 License. (c) Association for Education in Journalism and Mass Communication, 2016. 


\title{
Team Teaching of Creative Advertising and Public Relations Courses
}

\begin{abstract}
Advertising and public relations are complex practices, and it is challenging for educators to find instructors who can fulfill expertise across disciplines, particularly in creative applications involving technology. Team teaching is one approach to provide multiple proficiencies. This paper describes how two co-taught courses, Design for Advertising and Public Relations and Commercial Production for Advertising and Public Relations, were developed, delivered and assessed. A literature review of team teaching and creative instruction provides a framework for course designs and student surveys. Course evaluations and instructor reflections are the evidence used for evaluation. The study is important, as specialties from multiple practices, including those that require technology, are increasingly necessary for preparing students for these industries. The study adds to the literature about team teaching and provides a foundation for effectively collaborating on creative courses.
\end{abstract}

Pamela K. Morris, Loyola University Chicago

\section{Introduction}

Advertising and public relations are interdisciplinary, complex and creative practices. Advertising agencies are made up of multiple departments, such as creative, research, media, traffic, planning and account management. While each is unique, all areas need to function together to develop strategic and innovative solutions for client communication challenges. Technology increasingly is involved with special software for each discipline and is an especially important part of the creative process.

Both creativity and training for creativity were identified as areas ripe for improvement in an investigation of undergraduate advertising programs (Stuhlfaut, 2007). Moreover, new forms of media have made visual (Stuhlfaut \& Berman, 2009) and online video communication (Beard \& Yang, 2011) more important. While students need to be prepared for these opportunities, finding instructors with multiple expertise is difficult. Consider that for a course on designing advertisements, teachers require: an understanding of the advertising and public relations development, strategy and creative process; design concepts such as layout, color and type; and skills for software programs, such as PhotoShop, InDesign and Illustrator. Likewise, in order to instruct classes on television, video, digital or other commercial broadcast production, instructors require the advertising process knowledge just mentioned, in addition to proficiencies in video, filming, lighting, editing, sound, production and Adobe Premiere Pro or similar technology.

An approach to bring together the multiple experiences required to instruct advertising and public relations courses, especially the training for creative and technology skills, is through team teaching. A teaching team can blur disciplinary boundaries, integrate various perspectives and help make courses more relevant to industry (Gaytan, 2010; Smith Ducoffe, Tromley \& Tucker, 2006). It is also a way for the academy to maintain pace with business practices.

The purpose of this study is to understand better the team teaching approach in creative classes unique to advertising and public relations through assessing student surveys, course evaluations and instructor reflections. The current exploration is based on multiple sessions of two team-taught courses offered at a private Midwestern university. The paper provides educators with a useful context and benchmark for team-taught course development and further research in this area of pedagogy.

\section{Literature Review}

The first use of team teaching is attributed to William Alexander, known as the father of 
the American middle school, while he was attending a conference at Cornell University in 1963. Alexander's intent was to create teams of teachers to instruct relatively large groups of students (Gaytan, 2010). Teacher collaboration, co-teaching (Wang, 2012), shared teaching (van Amelsvoort, van Wijk \& den Ouden, 2010) and interdisciplinary teaching (Smith Ducoffe et al., 2006) are related variations on the concept.

According to Davis (1995), team teaching is "All arrangements that include two or more faculty in some level of collaboration in the planning and delivery of a course" (p. 8; see also Buckley, 2000). Parada and Franch (2008) considered instructional methods, activities and course content to describe three forms of team teaching: parallel, rotational and interactive (as cited in van Amelsvoort et al., 2010). Parallel, the most elementary style, involves multiple instructors teaching in the same course separately on different days. Most often used for first-year undergraduate introductory courses, classes may be large as many as 500 students. Rotational, the next level, is applied when two instructors, usually from the same department, create a course and split the lecture content. The format is suited for later years of a bachelor's program. For the most evolved style, interactive teaching, instructors work together to plan and create a course and blend content from the start. Such methods are appropriate for upper divisions and at the master's level (van Amelsvoort et al., 2010).

A similar model, interdisciplinary teaching, takes place when scholars from two or more disciplines, subdisciplines or professions come together and integrate their unique perspectives (Davis, 1995; Smith Ducoffe et al., 2006). Integration is particularly important in interdisciplinary courses, as it is necessary for instructors not only to present material from their different areas, but also to weave the proficiencies together and demonstrate how they are linked. Integration can be placed on a continuum, from courses taught with subjects in silos to the other extreme, where practices are related and shown to enhance one another (Smith Ducoffe et al., 2006).

More than one instructor may be necessary to effectively integrate material, and interdisciplinary courses are commonly team-taught (Smith Ducoffe et al., 2006). Team teaching can be ranked based on collaboration. At one extreme are courses that are planned jointly but taught separately, and on the other end are courses planned and taught together. Collaboration is positively related to integration: that is, the more collaboration the more integration. Studies have shown the higher the perceived amount of integration, the more positive the course rating (Smith Ducoffe et al., 2006).

Team teaching is a major commitment for those involved, including faculty, administration and staff. It takes more time and effort than teaching alone (George \& Davis-Wiley, 2000; Smith Ducoffe et al., 2006; Sorensen \& Wittmer, 1996), with increased planning and coordination in deciding topics to be covered, managing grading and directing all other course activities. Teachers must practice or learn new skills, develop joint pedagogical strategies and manage their own egos (George \& Davis-Wiley, 2000; Smith Ducoffe et al., 2006). Like most group efforts, teaching teams must build trust, communicate effectively, foster an open climate and resolve conflicts (Bakken, Clark \& Thompson, 1998; Smith Ducoffe et al., 2006; Sorensen \& Wittmer, 1996). In addition, Armstrong (1980) suggested that faculty may need to step outside of their individual comfort zones and relinquish control in the classroom (Smith Ducoffe et al., 2006).

\section{Benefits of Team Teaching}

Despite the challenges, team-taught courses compare favorably with traditional, solo instructor courses (Davis, 1995; Smith Ducoffe et al., 2006), and team teaching offers multiple benefits, some of which are summarized below.

Reach more students. Many factors like age, cultural background, learning potential, learning skills, psychological readiness, motivation and outlook affect student learning. Two teachers with different personalities and backgrounds together are better able than one instructor alone to address students' various needs, interests, attitudes and other issues (Buckley, 2000).

More feedback. Studies have shown that students get more feedback from teamteaching learning environments, as multiple instructors have twice the capacities to devote to students (Gaytan, 2010; Wadkins, Miller \& Wozniak, 2006).

More interesting and effective lectures. Two teachers can make lectures livelier, more engaging and more memorable (Buckley, 2000). Van Amelsvoort et al. (2010) described how two instructors can use an interactive format to keep lectures active and reinforce meaningful points. One instructor can take a leading role, while the other acts as a discussant to raise questions, provide criticisms and make suggestions. Professors can interrupt 
and challenge one another, involve students in different ways and help provide relevance to particular topics. These types of tactics encourage students from passive to active learning (Smith Ducoffe et al., 2006) and engage higher-order intellectual skills (Buckley, 2000).

Fosters independent thought. The exchange of two instructors can set an example for how to use critical skills of synthesis, analysis and evaluation, while at the same time show respect for the material and each other. The dialogue from professors' unique perspectives can illuminate that there may be more than one right answer, encouraging independent thought (van Amelsvoort et al., 2010). As students join discussions and attempt to articulate their ideas, the process can foster open self-expression, encourage active participation, improve creativity, enhance communication abilities and strengthen interpersonal relations (Buckley, 2000). These particular proficiencies are especially critical for brainstorming and critiques that are part of the advertising and public relations strategic and creative development process.

More holistic learning. Two teachers with different expertise and points of view offer interdisciplinary learning. A study of several team-taught courses at a business school found that students rated such courses as "more valuable" to their learning (Smith Ducoffe et al., 2006, p. 290). Others suggested interdisciplinary learning, often associated with team teaching, encourages holistic thinking (Auman \& Lillie, 2008; Kraeplin \& Criado, 2005).

\section{Planning Team Teaching}

Planning team-teaching courses requires extra care and collaboration between professors (Gaytan, 2010; Hammer \& Giordano, 2001). Consensus on all aspects of the course, from topics and instructional strategies to materials and evaluations, needs to be reached prior to the start of the class. Buckley (2000) suggested teachers maintain their individual personalities, own classroom styles and unique teaching techniques, and allow differences to complement one another.

In order to be part of the subject and course, Gaytan (2010) advocated that faculty attend all classes, sit among students and interact with them to help with comprehension of the material. Others proposed that instructors not leading the lecture can provide a model for learning by asking questions to generate relevant responses, facilitate meaningful discussions and engage students (Hammer \& Giordano, 2001), behaviors cited to result in positive student learning outcomes (Leavitt, 2006; as cited in Gaytan, 2010). Creating consistent grading standards is especially salient, and grading rubrics are highly recommended to avoid student confusion (Gaytan, 2010).

\section{Team Teaching}

The following provides details of the planning, implementation and assessment of two team-taught courses offered in the School of Communication at a private Midwestern university.

\section{Course Design}

With the goal to address the unique characteristics of creative, strategic and persuasive print design and video commercial production, faculty in advertising and journalism (specifically experts in design and film) created two special topic courses: 1) Design for Advertising and Public Relations and 2) Commercial Production for Advertising and Public Relations. An advertising/public relations professor (with over 20 years of experience at a leading global advertising agency as a vice president and account director) co-taught both courses, along with an active designer in the former and an award-winning filmmaker in the latter. Course objectives were threefold:

- Offer courses that integrate design and multimedia broadcast production skills with the specialty of advertising and public relations;

- Create courses that are studentcentered, encourage independent thinking and foster active experiential learning;

- Incorporate the university's and School of Communication's missions, particularly ethics, social justice and service learning, into learning goals.

\section{Course Attributes Developed Together}

Literature suggested that the central idea of team teaching, which guarantees its effectiveness, lies in two instructors both planning and presenting a course together (van Amelsvoort et al., 2010). With this in mind, instructors jointly developed descriptions and learning goals for each course, ensuring that the different disciplines were covered.

After course concepts had been approved by the advertising/public relations and journalism faculties, the two teachers brainstormed assignments based on learning objectives and with specializations in mind. Textbooks were also considered and selected at an early stage of planning. From these parameters, the coteachers collaborated on a syllabus for about two months during the summer through in- 
person meetings and email exchanges. Class topics, lectures, readings, in-class activities, assignments and tests were determined together.

In keeping with the hands-on type of learning found most effective in advertising and public relations instruction (Stuhlfaut \& Berman, 2009), assignments were project-based and applied. Each task provided a communication challenge and required students to actively immerse themselves in the lesson material, take initiative and work through the entire advertising and public relations strategic development process, from preparing background research, identifying campaign objectives and target audiences, developing creative briefs, to designing and filming advertisements or videos and presenting and selling the finished pieces.

Depending on the term, students in the Design course worked solo to complete six to eight projects, while in Commercial Production four or five team-based assignments were required. Graduate students were given additional work. Some of the projects were for non-profit organizations and creative competitions, such as the Super Bowl Doritos commercial contest. Grading rubrics were created for each course that incorporated particular specialties.

\section{Course Attributes Developed Individually}

Other course content was developed individually based on expertise. While assignment ideas were affirmed prior to the semester, both teachers wrote directions and criteria for their parts closer to the project's introduction. The design and film instructors detailed layout, type, editing, photography, sound, music and other technological requirements, while the advertising/public relations faculty outlined objectives, strategy and milestone due dates. Instructors combined their parts into one document and continued to review details until each was satisfied. When instructors agreed on the specifics, one of them volunteered to post the file to the online course portal and make copies for distribution in class.

Similarly, instructors lectured and supervised class activities based on their professional area. Principles of design, color, type, space and other related topics and software instruction for InDesign, PhotoShop and Illustrator were taught by the design specialist, while video and broadcast production skills, such as shooting, lighting, editing, green screen techniques and Adobe Premiere Pro software learning, were given by the filmmaker. In both courses the advertising practitioner provided perspectives on creativ- ity, branding, positioning, strategy, targeting, creative brief design, business writing and presentation methods. During lectures the other instructors participated by actively listening, adding perspectives, asking questions and offering examples.

\section{Other Pre-Semester Coordination}

Other pre-semester organization and planning that are never a consideration when teaching alone were necessary. Instructors contemplated class leadership styles as suggested by Buckley (2000) and decided to share leadership roles, and follow areas of expertise to offer their own different perspectives in lectures, critiques and discussions. Teachers also agreed that each would attend all classes to set an example of active learning and to fully integrate into the course, both important characteristics for team teaching (Gaytan, 2010; Hammer \& Giordano, 2001).

Extra details, such as identifying overlapping office hours to ensure times for students to visit with both instructors, and jointly preparing upcoming classes and grading were established.

\section{Method}

With the goal to understand the team-teaching experience, several semesters of two teamtaught courses, Design for Advertising and Public Relations and Commercial Production for Advertising and Public Relations, were analyzed. The author, a former account director in a multinational advertising agency, cotaught both courses with creative specialists - a designer, in the former, and a filmmaker, in the latter. The three faculty included an African American female and Caucasian male and female, with ages ranging from 35 to 60 years old. Two of the teachers were full time professional-in-residence instructors, while the third was a tenure-track professor. All had or were currently working in industry in their specialty areas.

Data were collected from multiple sources, including a survey designed specifically to gain insights about team teaching and general university course evaluations that captured student perceptions of the experience. In addition, instructor reflections provide perspectives and details for the approach. The following offers details for the team teaching survey and general course evaluation formats.

\section{Student Surveys}

Based on the literature, several areas were identified for investigation in a survey format.

Awareness and experience. Three questions aimed to assess awareness and experience of team teaching. The first, "Have you ever 
taken a course with two instructors before?" could be answered "Yes" or "No," and "If yes, which ones(s)?" The second question, "What did you notice when you registered for the course?" offered two choices: (1) "Noticed two instructors were listed" or (2) "Did NOT notice two instructors were listed." The third inquiry, "What does team teaching do to your interest in the course?" allowed respondents to choose from three options: (1) "Increases interest," (2) "Decreases interest" or (3) "No change in interest."

Desirable student characteristics. An attempt was made to identify attributes that students find helpful in excelling in the team-teaching environment. The literature suggested that independently minded students may be desirable, as they need to take direction from two professors, and the co-teaching process itself encourages independent thought (van Amelsvoort et al., 2010). Similarly, two professors can model the process of synthesis, analysis and evaluation in their instructions, thereby helping students to use their critical skills (van Amelsvoort et al., 2010). The process can also inspire holistic thinking (Auman \& Lillie, 2008; Kraeplin \& Criado, 2005) and creativity (Buckley, 2000). To this end, the survey inquired whether students viewed being independent and having critical and creative skills as important traits for excelling in a co-teaching course.

The more students participate in active learning, the more they will gain from the material (Smith Ducoffe et al., 2006). Inclass participation requires a certain amount of effective communication and interpersonal skills, as well as respect for others. While team teaching can foster an active and engaging environment, it can also help strengthen these particular qualities (Buckley, 2000). Students were asked to rate how important it was to possess the attributes of active participation, good communication, interpersonal skills and having respect for others in order to excel in this type of atmosphere.

Students were asked to select the three most crucial characteristics for students out of the seven key qualities previously reviewed (independent, critical skills, creative, active participation, good communicator, interpersonal skills and respectful). Specifically, the survey inquired: "What characteristics of a student are needed for a successful teamteaching environment? Please select the top 3."

Desirable teacher characteristics. The team teaching model may not be for everyone (Wadkins et al., 2006), and the literature describes attributes faculty members should possess in order to be effective in co-teaching situations. Smith Ducoffe and colleagues (2006) considered team teaching based on collaboration and posited that more collaboration increases student ratings of the course. When teaching jointly, professors must be good communicators with one another and with students, and work through problems and issues as they arise to keep courses moving (Bakken et al., 1998; Smith Ducoffe et al., 2006; Sorensen \& Wittmer, 1996). Students were asked to rate the importance of faculty's ability to communicate and collaborate.

The key to fruitful collaboration is being organized, respectful and trusting. When working with a co-teacher, consideration needs to be given to the partner's perspectives, schedule and plans, different than when teaching alone, when one may be able to decide at the last minute the lecture topic or assignment. Respecting the co-teacher and his or her efforts, opinions, style and time, makes for effective collaboration. As in any group, building trust is also important (Bakken et al., 1998; Smith Ducoffe et al., 2006; Sorensen \& Wittmer, 1996).

A number of studies proposed that team teaching takes more time and effort in planning and coordinating courses (e.g., George \& Davis-Wiley, 2000; Smith Ducoffe et al., 2006; Sorensen \& Wittmer, 1996). The additional efforts required compared to teaching solo suggest that a co-teaching instructor is committed to his or her work as an educator. Although it may take extra time, learning to weave specialties in with another area, learning new skills and stepping outside of one's comfort zone may make co-teaching more exciting (Armstrong, 1980; Smith Ducoffe et al., 2006). This also implies that team-teaching professors require the ability to adapt and be open-minded, both while preparing the course and in the classroom (Bakken et al., 1998; Smith Ducoffe et al., 2006; Sorensen \& Wittmer, 1996). For these concepts, students were asked if committed, adaptable and openminded were key qualities for team-teaching professors.

On the other hand, as professors are experts and scholars in their respective fields, sharing in preparation and classroom lectures may be difficult (Armstrong, 1980). More than one researcher has suggested that instructors must handle their own egos when team teaching (e.g., George \& Davis-Wiley, 2000; Smith Ducoffe et al., 2006), and their ability to do so was the final attribute students evaluated.

In summary, students were asked: "What 
characteristics of a professor are needed for a successful team-teaching environment? Please select the top 3." The list provided nine different characteristics: collaborative, good communicator, committed, adaptable, openminded, organized, respectful, trusting and manages his/her own ego.

Style considerations and contradictions. The literature recommended that co-teachers consider instruction styles when planning collaborative courses and that each maintain their individual personalities and classroom techniques, and work to complement one another (Buckley, 2000). The concept of teaching style variations was measured with the following question and answer options: "In this arrangement, which do you think is more important?" (1) "Teaching styles of each professor should be the same;" (2) "Teaching styles of each professor should be different;" or (3) "Teaching styles of each professor don't matter."

Acknowledging the danger of contradicting one another in the classroom, the survey directly inquired: "Have there been times when the two professors contradicted one another? If yes, please explain."

Value perceptions. Team-taught courses were found to be valuable in a study at a business school (Smith Ducoffe et al., 2006). Students' value perception of the co-teaching experience was operationalized by asking them to rate their level of agreement on a Likert-type 5-point scale ("Strongly disagree" to "Strongly agree") with four statements: (1) "Having two professors teach a single course is unusual;" (2) "The team-teaching approach serves students' needs;" (3) "Two professors in the same classroom for each session provides twice the value of the learning experience;" and (4) "I would take another team-taught course."

Advantages and disadvantages. Two separate open-ended questions, "What are the advantages of having two professors for a single course?" and "What are the disadvantages of having two professors for a single course?" allowed students to write thoughts about their experiences in the team-taught courses.

Demographics. Lastly, basic demographics were captured, including year in school (freshman through graduate), major (advertising/ public relations, journalism, communication studies, film and digital media, graduate or other) and gender.

The survey was administered four times over two academic years (fall 2013 to spring 2015) when the two courses, Design for Advertising and Public Relations and Com- mercial Production for Advertising and Public Relations, were offered. Participation was voluntary and 48 students enrolled in classes at the time completed questionnaires. Representation from the two courses is equally split. Females $(54 \%)$ slightly outnumbered males across both classes and all four semesters. Seniors $(38 \%)$ represented the largest proportion, followed by juniors (29\%) and graduates $(25 \%)$, with sophomores $(8 \%)$ making up the balance. Slightly more than half $(54 \%)$ the students were advertising/public relations majors, with graduate studies $(25 \%)$ in second place. Film and digital media $(13 \%)$, communication studies $(6 \%)$ and journalism $(2 \%)$ concentrations also were represented.

\section{Course Evaluations}

At the end of the semester students are expected to appraise courses via an online questionnaire system. While not mandatory, the university sends multiple email messages strongly encouraging students to complete the form. Responses used in the analysis came from the open-ended request for students to "Use the space provided in the text area below for your comments."

\section{Findings}

With the specific purpose of learning about students' perceptions of team-teaching efforts, two team-taught courses were studied over two years. Multiple sources of evidence were used in the evaluation, including specifically designed surveys, qualitative responses from general university course evaluations and instructor reflections.

Awareness and experience. For most $(83 \%)$ students, these were their first teamtaught courses. Nearly all $(90 \%)$ students indicated that they had noticed two instructors were listed when enrolling in the class. When asked if the team-teaching method made them increase, decrease or have no change in interest, two thirds reported that it increased their interest, while $31 \%$ believed it made no change in their interest level for the course.

Desirable student and teacher characteristics. Two questions attempted to capture students' perceptions for attributes that result in successful team teaching. For characteristics of students, respondents were asked to select the three most significant qualities from a list of seven traits. A little more than two thirds of the participants suggested that students need to actively participate $(69 \%)$ and be good communicators (67\%). Being respectful $(54 \%)$ was the third most popular, and having interpersonal skills (48\%) followed. On the other hand, critical and creative 
attributes (38\% and $33 \%$ respectively) and being independent $(21 \%)$ were rated not as important.

Students were also probed for specific qualities that professors needed to have in order to be effective in team teaching. Students selected three characteristics from nine alternatives. Ranking at the top were collaboration (71\%), being organized (54\%), being a good communicator $(52 \%)$ and being open-minded $(44 \%)$. Students thought that being adaptable (31\%), respectful $(29 \%)$, managing his/ her own ego $(27 \%)$, committed $(19 \%)$ and trusting $(10 \%)$ were not as valuable for teachers.

Style considerations and contradictions. About half (48\%) of the students believed that each instructor's teaching style should be different, compared to $27 \%$ who thought they should be the same. A quarter believed that teaching styles did not matter. Slightly more than half $(52 \%)$ reported that professors had contradicted one another. When asked to explain, students indicated that they perceived the contradictions as beneficial, such as: "Professors had different creative opinions about projects," "Differing opinions on the strength of an ad," "Disagreements about if something was effective" and "What makes a good commercial/things that can improve a commercial. But I found this helpful."

Moreover, students identified that the contradictions were based on the different perspectives and expertise that instructors brought to the class. Responses on this theme included: "Not contradicted, but had different skills" and "Being from slightly different backgrounds they had different opinions on certain aspects." Just as important, the professional consideration and delivery of the varying viewpoints were also noticed by students, as they wrote: "It was handled respectfully and well" and "But only for the sake of a good debate."

Value perceptions. Students were split on whether having two professors was unusual. Half the students agreed or strongly agreed, $23 \%$ neither agreed nor disagreed, and 25\% disagreed. However, when asked to consider if two instructors served student needs, a large proportion $(88 \%)$ of students agreed or strongly agreed. Additionally, the majority $(66 \%)$ indicated that the team-taught courses supplied students with twice the value of their learning experience. And $90 \%$ agreed or strongly agreed with the statement that they would take another team-taught course.

Advantages. Students were asked to describe advantages of having two professors instruct a single course. Comments can be grouped into three themes: appreciating different perspectives, reaching more students with a variety of backgrounds and styles, and creating a more interesting class.

Many student statements acknowledged each instructor's different views, such as: "Teachers have different backgrounds - allow students to learn from 2 frames of mind," "You get 2 perspectives on everything. Each professor brings something different to the table" and "You receive even more knowledge on a subject from two different experiences and backgrounds and there's enough to go around."

A second theme was how the two professors offered alternative styles, personalities and backgrounds to help foster a connection in some way with individual students. Buckley (2000) suggested that due to variations in instructor demographics and personalities, together they are better able than just a single instructor to reach more students. In this case, the students wrote: "Double the knowledge, one is likely to teach in a manner closely related to your learning style," "There is more help and individual time" and "With two professors ... one professor's teachings may click with you better than the others."

Students also expressed in several remarks how the two teachers created an engaging and interesting class. The following comments fall into this category: "Each one is specialized in his or her area of subject, so the class is very enriching," "Students benefit from the knowledge that each professor brings to the table. Varying teaching styles keep students interested" and "Both professors bring their expertise to the subject matter. Not every student's major is the same, so those different perspectives are great!"

Disadvantages. When asked to list disadvantages of having two professors for a single course, seven of the 48 students wrote "None" or left the question blank. Of those who provided a reply, instead of citing specific examples, students wrote about the possibility of contradictions, as in: "If the two professors cannot get along then it can affect their teaching abilities," "If teachers couldn't cooperate/ don't communicate well it could lead to confusion for students" and "They might grade differently."

There were a few specific criticisms, including "More work," "Needing to hear back from both when questions outside of [the] classroom arise, or needing to wait for professors to consult one another for answer[s] to questions" and "Sometimes opinions conflict, making the student unclear about how to im- 
prove his/her work."

\section{Discussion}

The purpose of this study was to better understand the team-teaching experience, with a goal to improve collaboration efforts that contribute to the quality of student knowledge and learning. Team-taught courses are not very common, but they can be particularly relevant and can offer an effective approach for advertising and public relations instruction. The instructors' intent was to create industrylike practices and standards in the classroom through project-based and applied assignments, multi-tasking schedules and different professional perspectives for two team-taught courses: Design for Advertising and Public Relations and Commercial Production for Advertising and Public Relations.

The evidence of student sentiments found in responses from a custom-designed survey about team teaching and general course evaluations in this study reveals the benefits of team teaching in practice as outlined in the literature, including reaching more students, providing more feedback, giving more interesting and effective lectures, fostering independent thought, encouraging holistic learning and modeling industry. In addition, instructor reflections reinforce these and uncover other positive qualities of the team teaching model.

\section{Benefits of Team Teaching in Practice}

Reach more students. Through the collaborative courses faculty were able to reach more students, a benefit of team teaching, according to Buckley (2000). Student comments previously mentioned, as well as, "Having a variety of opinions. Having a greater opportunity for engagement" and "...one professor's teachings may click with you better than the others," exemplify the influence.

Although courses were advertising classes, about half the students were from other majors, such as communication studies, film, journalism and digital media and storytelling, and they benefited from learning about the advertising and public relations creative development process and career prospects. Gaining new insight and inspiration from the courses, some of these non-advertising majors later took advertising creative courses as electives, interviewed for entry-level positions at advertising agencies and started their careers in the business, including as assistant producers. Others assisted the author on advertising research projects. None of these relationships and opportunities would have been made without the dual nature of the course.
More feedback. Team-taught courses have also been shown to accomplish more, especially in offering students additional feedback (Gaytan, 2010; Wadkins et al., 2006). Pertinent student survey comments like "Get double the attention as well as two different experiences brought into the classroom per each professor's background," "More resources, multiple opinions," "Different opinions" and "More opinions," reveal the impact the multiple instructors made in each course.

More interesting and effective lectures. Not only did students report that they received more attention, but they also seemed to find courses more interesting, a condition that encourages higher-level learning (Buckley, 2000). "Varying teaching styles keep students interested," "A very interesting class that provides students an opportunity to add good work to their reels, while learning the basic fundamentals of advertising" and "Each one is specialized in his or her area of subject, so the class is very enriching" are student comments that paint a picture of their perceptions for how instructors aimed to provide interesting and relevant lectures.

Fostering independent thought. The different viewpoints and the engaging nature of the class recognized by students were conscious attempts by the faculty to encourage independent thought, as outlined by van Amelsvoort and colleagues (2010). The critiques and brainstorming that uncovered multiple solutions to a single task were ways for students to practice self-expression and creativity. Several students used the word "creative" in their survey and course evaluation comments, such as "It increases the value of the learning experience and allows for creative thinking" and "I enjoyed getting the chance to be creative and learn a little more about design."

Holistic learning and modeling industry. Students mentioned in surveys that each professor provided a different expertise. Interdisciplinary learning can encourage holistic thinking (Auman \& Lillie, 2008; Kraeplin \& Criado, 2005), and in these courses students identified and valued the different perspectives that instructors brought to classes. Respondents wrote: "Students get two different perspectives of the same field," "I get to learn different things from two different professors," "This course combines two fields, so having two professors is absolutely necessary" and "Different backgrounds + work experience allowed for increased learning in the industry, \& helped simulate [a] professional work environment." 
Interdisciplinary courses are cited to better model industry practice (Gaytan, 2010; Smith Ducoffe et al., 2006) and general evaluation thoughts reinforced this: "While at first this class focused on theory, terminology, and program use, the majority of the class was projects that mimicked real life assignments that are salient to my major" and "[G]reat course and [I] appreciated the breadth of knowledge both professors were able to bring to the table. [It] aided the presentation of material and learning so that the students can bring this knowledge into a professional setting."

These findings are important considering that instructors pondered how to present different opinions in the classroom and at first were careful to not disagree with each other. However, as the semesters progressed and instructors became more familiar with each other's teaching styles, they realized it was not only necessary, but also better to disagree and offer various perspectives, analyses and justifications in a respectful and professional manner.

\section{Stepping Outside Your Comfort Zone}

Instructors met regularly after each semester to reflect on class results. The experience revealed that while instructors were of different generations, backgrounds, ethnicities and genders, all have similar challenges. The team teaching approach helped all to become better teachers and acquire more knowledge within and beyond their own specialties.

By working through syllabi, lesson plans and grading, as well as observing others in the classroom, instructors gained different teaching methods and transferred those to their solo-taught courses. Instructors also could be better teachers knowing the unique attributes and what is acceptable and unacceptable in each area, such as grammar, punctuation and other writing styles, and the scripted and staged nature of advertisements compared to the objectivity of journalism, documentaries and film.

Learning about the other practice area also forced instructors to step outside their comfort zone, as suggested by Armstrong (1980) and Smith Ducoffe et al. (2006), and provided opportunities to advance their specialties. The designer has developed advertising campaigns to brand and bring awareness to the School of Communication and other organizations, worked with students on branding, advertising, Web sites and portfolios, and enhanced her Pinterest account with a section devoted to creative advertisement design. The filmmaker has reviewed thousands of international commercials, researched the advertising business, nurtured voiceover and other talent for student use, forged career opportunities and learned about current trends. He has transferred his multi-award winning filmmaking skills to create spec commercials for potential clients and contests.

The filmmaker also has introduced brand journalism, a growing area that "... allows businesses to target customers with useful, tailored editorial content while promoting their brand, values, and products" (Cole \& Greer, 2013, p. 673), to his journalism courses. As companies see the advantages for creating their own media to target consumers, not only will there be more opportunities for trained journalists, but it will be important for students to learn that while taking a position in a story may be different than the traditional objectivity of journalism, the communication still needs to be transparent and accurate. As a consequence of learning about advertising in the co-taught course, the instructor is able to lead students on current industry trends and practices with ethical standards.

\section{Limitations and Future Studies}

A limitation to this study is that it is based on student surveys and evaluations from two courses over two years and only in one university. Continuing the survey research could provide a larger sample and a crosstabulation analysis could compare perception differences by major. Additional explorations could review team teaching across the university or even the United States to identify the colleges, schools and departments employing the approach, detail the methods and instructional styles, and review assessments of effectiveness and learning outcomes. These team-taught courses could also be compared to those taught by single instructors to note any perception or learning outcome similarities or differences.

In-depth interviews of students could also be conducted to gain deeper understanding of their perceptions of team teaching. Particular aspects of the approach could be probed, including how co-teaching helped in student learning and what they specifically liked and disliked about the approach.

\section{Conclusion}

While new sophisticated technology has allowed nearly anyone with a smartphone or other mobile device can take pictures and videos to upload to Facebook and YouTube, communication practitioners will need to have these skills at a professional level (Beard \& Tarpenning, 2001). In addition, multinational advertising and public relations businesses will likely continue to have specialized departments with unique technol- 
ogy and software that will need to collaborate with one another. The team teaching model attempts to bring together the various perspectives of creative, production, planning and account management, and show how they collaborate to achieve a common goal, which makes these courses important.

However, co-teacher arrangements are unusual. Dedicating two professors to teaching in the same classroom can be difficult for administrators to manage and, as they must cover courses with a limited budget and be fair to faculty, team-taught courses bring up multiple issues. Primarily, do courses count for one or half a course and will online course portals and systems accommodate two or more instructors? Despite the challenges, the team teaching method helps student learning, reflects industry, provides opportunities for faculty development and is an example of a university's commitment to being innovative and progressive in its curriculum. Advertising and public relations are complex practices, as they are creative and multi-disciplined, and therefore teaching courses on the subject is just as complex. Team teaching is one style that can help better prepare the next generation of these professionals with the critical, analytical, creative and thoughtfulness necessary to be successful in communication careers.

\section{References}

Armstrong, F. H. (1980). Faculty development through interdisciplinarity. Journal of General Education, 32(1), 52-63.

Auman, A., \& Lillie, J. (2008). An evaluation of team teaching models in a media convergence curriculum. Journalism \& Mass Communication Educator, 62(4), 360-75.

Bakken, L., Clark, F. L., \& Thompson, J. (1998). Collaborative teaching: Many joys, some surprises, and a few worms. College Teaching, 46(4), 154-57.

Beard, F. K., \& Tarpenning, D. (2001). Teaching TV advertising creative using digital video on the desktop. Journal of Advertising Education, 5(1), 23-32.

Beard, F. K., \& Yang, A. (2011). Choosing and evaluating digital and online media: A conceptual/instructional model. Journal of Advertising Education, 15(2), 5-13.

Buckley, F. J. (2000). Team teaching: What, why, and how? Thousand Oaks, CA: Sage.

Cole II, J. T., \& Greer, J. D. (2013). Audience response to brand journalism: The effect of frame, source, and involvement. Journalism \& Mass Communication Quarterly, 90(4), 673-90.

Davis, J. R. (1995). Interdisciplinary courses and team teaching: New arrangements for learning. Phoenix, AZ: American Council on Education and the Oryx Press.

Gaytan, J. (2010). Instructional strategies to accommodate a team-teaching approach. Business Communication Quarterly, 73(1), 82-87.

George, M. A., \& Davis-Wiley, P. (2000). Team teaching a graduate course: Case study: A clinical research course. College Teaching, 48(2), 75-80.

Hammer, E. Y., \& Giordano, P. J. (2001). Dual-gender team-teaching human sexuality: Pedagogical and practical issues. Teaching of Psychology, 28(2), 132-33.

Kraeplin, C., \& Criado, C. A. (2005). Building a case for convergence journalism curriculum. Journalism \& Mass Communication Educator, 60(1), 47-56.

Leavitt, M. C. (2006). Team teaching: Benefits and challenges. Speaking of Teaching, 16(1), 1-4. Retrieved from https://web. stanford.edu/dept/CTL/Newsletter/teamteaching.pdf.

Parada, P., \& Franch, J. (2008). Team teaching. In P. Mårtensson, M. Bild, \& K. Nilsson (Eds.), Teaching and learning at business schools: Transforming business education (pp. 47-62). Aldershot, UK: Gower Publishing Company.

Smith Ducoffe, S. J., Tromley, C. L., \& Tucker, M. (2006). Interdisciplinary, teamtaught, undergraduate business courses: The impact of integration. Journal of Management Education, 30(2), 276-94.

Sorensen, J. E., \& Wittmer, D. P. (1996). Stage 2: Designing team-taught transdisciplinary courses - Where do we begin? Journal of Management Education, 20(4), 422-34.

Stuhlfaut, M. W. (2007). How creative are we?: The teaching of creativity theory and training. Journal of Advertising Education, 11(2), 49-59.

Stuhlfaut, M. W., \& Berman, M. (2009). Pedagogic challenges: The teaching of creative strategy in advertising courses. Journal of Advertising Education, 13(2), 37-46.

van Amelsvoort, M., van Wijk, C., \& den Ouden, H. (2010). Going Dutch or joining forces? Some experiences with team teaching in the Netherlands. Business Communication Quarterly, 73(1), 96-101.

Wadkins, T., Miller, R. L., \& Wozniak, W. (2006). Team teaching: Student satisfaction and performance. Teaching of Psychology, $33(2), 118-20$. 